\title{
An approach to identifying micro behavior: how banks' strategies influence financial cycles.
}

\author{
Gabriele Tedeschi \\ Department of Economics \\ Universitat Jaume I, Castellon, Spain \\ E-mail: gabriele.tedeschi@gmail.com \\ Maria Cristina Recchioni \\ Department of Management \\ Università Politecnica delle Marche, Ancona, Italy \\ E-mail: m.c.recchioni@univpm.it \\ Simone Berardi \\ Ministry of Economics and Finance, Italy* \\ E-mail: simone.berardi@mef.gov.it \\ February 13, 2019
}

\begin{abstract}
In this paper, we show that the values of parameters of a wellcalibrated model are useful in detecting micro behavior. We use a calibration procedure suitable for validating agent-based models to show how the evolution of model parameters, obtained via a rolling window estimation, illustrates the evolution of agents' strategies in response to different economic conditions. In this regard, we calibrate the well-known financial model of Brock and Hommes using three banking indices (i.e., the S\&P SmallCap 600 Financials Index, the STOXX Europe 600 Banks, and the STOXX Asia/Pacific 600 Banks) running from 1994 to 2016. The choice of a spatially and temporally diversified dataset allows us to analyze differences and similarities in the behavior of banks belonging to the different macro areas, as well
\end{abstract}

${ }^{*}$ The views expressed in the articles are those of the authors and do not involve the responsibility of the Ministry. 
as to capture agents' reaction to the several economic phases characterizing the time series investigated.

JEL codes: C52; C63; G15.

Keywords: Microfoundations, validation, agent-based models, heterogeneous beliefs.

\section{Introduction}

One of the key points of economic research is to understand how to describe and synthesize the myriad of disparate individual behaviors. In order to achieve a coherent behavior, a representative agent framework is usually adopted in most economic-models (see Stigler and Becker 1977, Blaug 1992 and Kirman 1992, among the first studies). On the one hand, this approach eliminates the problem of the infinite degree of freedom in the choice of agents' decision-making rules. On the other hand, it reduces, via reductionism, aggregate entities to concepts and knowledge for the lower-level domain of the individual agent, therefore blocking from the outset any understanding of the interplay between the micro and macro levels. Without entering into merits and/or limitations of the microfoundations ${ }^{1}$, what is sure is that this approach still dominates the way economists model agents' behavior. Following different lines of research, the economic literature identifies, at least, two other ways to identify agents' behavior in market. The first is experimental economics, that is, the application of experimental methods to study how human subjects behave (see, among many, Hommes et al. 2005; Bao et al. 2013; Husler et al. 2013 and Agliari et al. 2016). And the second is agent-based economics, that is, the application of computational techniques to reproduce micro-/meso- and macro-dynamics via a bottom-up approach (see, Arthur 1993; Clark 1997; Tesfatsion and Judd 2006; Shoham et al. 2007).

Following this last line of research, this paper is explicitly concerned with the ability of agent-based models to describe micro behavior. In this regard, the agent-based literature mainly focuses on input validation, which ensures that the behavior of individual agents incorporated into the model captures the salient aspects of human subjects (see Tesfatsion 2013; Tedeschi et al. $2012 \mathrm{~b}$ ). The approach we follow in this paper is, instead, quite different. We start with a microfounded agent-based model, namely the well-known model developed by Brock and Hommes 1997 (BH hereinafter), and show how the

\footnotetext{
${ }^{1} \mathrm{~A}$ discussion on advantages and disadvantages of this approach is beyond the scope of this work. A detailed debate can be found in other studies (see, for instance, Kirman 2010).
} 
calibrated values of the model parameters can describe real agents' behavior $^{2}$.

It is important to recall that in the literature on the agent-based model calibration (see Chen et al. 2012 and Bargigli 2017 for a detailed review), the estimation of the $\mathrm{BH}$ model has a long tradition (see, among many, Boswijk et al 2007; de Jong et al. 2009, 2010; Manzan and Westerhoff 2007; Reitz and Sloppek 2009; Kukacka and Barunik 2017). Indeed, even if other types of financial agent-based models, ranging from ant-type models to Lux models, have been calibrated using different techniques, including the ordinary least squares and maximum likelihood methods (see, for instance, Alfarano et al. 2005; Gilli and Winker 2003; Chen and Lux 2015; Ghonghadze and Lux 2016; Bargigli et al. 2014, 2018), the strong dominance of models deriving from the $\mathrm{BH}$ adaptive belief system is beyond doubt. This is due to its simplicity, its analytical tractability and the small number of parameters, all elements which make this model suitable for the empirical estimation.

Our work is closely related to Recchioni et al. 2015. There, the authors consider the $\mathrm{BH}$ model and estimate the model parameters with a non-linear constrained least-squares problem solved with a local minimization algorithm. Specifically, they identify the set of model parameters by minimizing a loss function. This function is the sum of the squared residuals, which are computed as the difference between the observed and simulated market price on a given date. The emphasis of that paper is on the methodological approach. The authors are interested in analyzing the accuracy of their calibration procedure in reproducing price dynamics under different modeling assumptions. To this end, the authors show the robustness of their technique both in-sample and out-of-sample. What we propose here, instead, is conceptually different. Starting from the aforementioned technique, this article tries to answer an important research question: how can we identify agent behavior in markets? In fact, the direct observation of individual behavior remains a very controversial problem of economic theory. This work proposes an alternative approach that can indirectly catch those strategies that are often latent and therefore not easily detectable. Given the abundance of the available aggregate data, what we suggest is a methodology capable of grasping micro-behaviors while observing macro-phenomena. In particular,

\footnotetext{
${ }^{2}$ It is worth noting that the BH model is not a "pure" agent-based model, that is, it does not describe the interaction of myriad heterogeneous agents, but rather synthesizes the heterogeneity through "macro" groups/families of agents.
} 
we investigate the possibility of describing the evolution of agent behavior by using the time series of $\mathrm{BH}$ model parameters estimated on aggregate data. In this regard, two simplifications of the BH model are needed. First, we use the simplest version of the model, where just two groups of traders compete in the market. In fact, as shown by Hommes 2001, the introduction of several behavioral strategies can generate chaos, strange attractors, and local bifurcation in the price dynamics, all important patterns which are not present in the time series considered. Second, in order to understand the dynamics of the "pure" strategies applied by agents in the markets investigated, it is important to remove the noise in the model while understanding the emerging properties in a deterministic skeleton. Thus, we assume constant dividends and a piecewise constant fundamental price. The latter means that we keep a constant fundamental price in the calibration window while updating it when the calibration window changes.

We are aware of the limitation of this assumption, especially in light of recent work which endogenizes the fundamental price in the BH model (see, for instance, Gori \& Ricchiuti 2018; Lengnick \& Wohltmann 2013; Naimzada \& Pireddu 2014; Proaño 2011; Westerhoff 2012). Nevertheless, we think this simplification is crucial to eliminating any exogenous noise which could interfere with the interpretation of the estimated parameters ${ }^{3}$

Given the potentially large implications of banks' behavior for the real economy and financial markets, and with the current crisis in mind, we have decided to apply our approach to identifying banks' behavior in financial markets ${ }^{4}$.

Banks are the main link between financial markets and real economy. They should provide financing to the private sector and pursue economic growth. However, in recent decades, they have transferred a massive amount of resources from the productive to the financial sector. This spectacular expansion and the growing influence of the financial sector do not seem to

\footnotetext{
${ }^{3}$ However, we assess the reliability of the piecewise constant fundamental price by comparing the results obtained under this assumption with those obtained by the $\mathrm{BH}$ model under a fundamental price based on the Gordon growth models (see, Boswijk et al. 2007, for further details).

${ }^{4}$ Although the methodology proposed in this paper is applied to banking behavior, we aim for a wider application of this approach. Specifically, we think that our technique able to deduce the micro behavior by studying the value of the parameters estimated on aggregate series can be applied to different markets
} 
have promoted the economy, which is instead affected by recurrent crises (see Orhangazi 2008 and Rochon and Rossi 2010). Yet global banking linkages are viewed as having spread the profound difficulties due to the financial crisis that began in industrialized countries in 2007 (see, for instance, Fasika and Pozo, 2008; Kalemli-Ozcan et al. 2013; Grilli et al. 2015, 2015b). Such considerations prompted the International Monetary Fund's April 2009 World Economic Outlook (WEO) to argue that global bank linkages are "fueling the fire" of the current crisis (p. 149).

To understand what banks do when confronted with shocks becomes a key question for evaluating the stability of the economic system. Banks' strategies are not only a powerful channel of crisis transmission, but also an instrument of crisis prediction (see Bernanke and Gertler 1990, 1995; Delli Gatti et al. 2005; Tedeschi et al. 2012 and Chen 2015 ).

In light of the recent banking crises and their tragic repercussions on the real side of the economy, we focus on analyzing banks' behaviors, which are seen as a primary reason for the financial crisis. To this end, we estimate the BH model on the daily closing values of the S\&P SmallCap 600 Financials Index, the STOXX Europe 600 Banks, and the STOXX Asia/Pacific 600 Banks from 30 December, 1994 to 18 May, 2016. These important banking indices reflect agents' strategies from different angles. First they incorporate information on the behavior of the banks which make up the index. Specifically, the selected financial instruments are chosen as being representative of different geographical areas $^{5}$ (i.e., USA, Europe and Asia) while the time period considered is relevant due to the presence of different economic phases. It is worth noting that there is empirical evidence that the dynamics of these financial instruments, which are seen as a proxy for common bank soundness and financial stability conditions (see Bologna and Caccavaio, 2014), is closely related to the motion of the banks' total foreign claims in the USA, Europe, and Asia as published by the Bank for International Settlement (BIS) 2018. This co-movement shows that these financial instruments reflect, at least partially, the strategies adopted by the banks making up the indices themselves. Second, these indices also reflect the perception of the economic actors trading them. In this regard, it is well-known the considerable impact of traders' expectations on price motions and, the consecutive feedback on agents' strategies (see, for instance, De Long et. al 1990 and Heemeijer et al. 2009). These indices, therefore, allow us to jointly detect

\footnotetext{
${ }^{5}$ In Sec. 3.4, we also show some preliminary results regarding the impact of banks bigger in size on strategies and the resulting effect on financial cycles. To this end, we estimate the $\mathrm{BH}$ model on the daily closing values of the S\&P 500 Financial index
} 
the direct behavior of the financial institutions and the indirect expectation of investors speculating on banks' equity. Last but not least, the indices, being aggregate indicators of markets' performances, leave the estimated parameters to describe the micro behavior without this being ex-ante included. In this regard, our idea is that micro behavior should emerge from the value of parameters estimated on time series which incorporate different economic phases. These different economic cycles should, therefore, produce variations in the estimated parameters' values and allow us to detect changes in agents' strategies.

Two steps are essential in achieving our goal. First, we have to prove that the BH model can successfully reproduce the daily price time series of the three banking indices investigated. To this end, we show that the simulated market prices generated by the BH model match the observed prices even when they are affected by abrupt changes. Specifically, we show that the relative errors are $0.7 \%$ on average. This first step consists in verifying that our calibration procedure succeeds in validating the output. This analysis, briefly sketched in this work, is widely debated in Recchioni et al. 2015.

Second, having successfully proven our calibration for output validation, we can test its efficiency in describing agents' behavior. The key idea of our approach is simple: if the calibrated $\mathrm{BH}$ model reproduces the dynamics of the investigated markets well (i.e., step 1), one can infer that the values of its estimated parameters may be useful in understanding the evolution of the behavior of agents operating in those markets (i.e., step 2). This second step, which is the original contribution of the present paper, requires us to estimate the model parameters using rolling time windows for each of the three banking series. In this regard, two exercises are presented: a long-run analysis where the emphasis is placed on differences and similarities among the three different geographical areas (i.e., America, Europe, and Asia), and a short-run analysis where the focus is on the dynamic evolution of banks' strategies in response to the several economic phases characterizing the time series investigated. Specifically, in the long (short) run analysis, the model parameters are calibrated approximately every year (two months) always using a year of past observations ${ }^{6}$. After each year (two months), we solve the calibration problem again, adding the 200 (60) new daily observations and discarding the $200(\mathbf{6 0})$ oldest ones. In this way, the length of the time window used in the calibration is kept constant. Hence, we solve 26 (90)

\footnotetext{
${ }^{6}$ In our analysis, one year of data corresponds to 200 observations, while two months correspond to 60 observations.
} 
calibration problems and the solutions to these problems provide series of each model parameter.

On the one hand, our long-run analysis shows the presence of strong similarities among the three areas. Indeed, in line with other studies (see Boswijk et al 2007, Recchioni et al. 2015), all three areas are characterized by the presence of collective behavior, also known as herding behavior, and the predominance of trend-follower behavior. The preponderance of the chartist strategy, with its well-known role in destabilizing prices, appropriately reflects the several financial crises characterizing the time series investigated (i.e., the years ranging from 1994 to 2016). Additionally, our results show that all countries are distinguished by very high levels in the risk-aversion parameter, in accordance with the registered financial turbulences.

On the other hand, our short-run findings suggest the key role of banks' strategic behavior in generating financial distress. In fact, we show that not only are price bubbles generated by a high percentage of chartist traders, but financial collapses are also heralded by a sharp increase in the number of these agents. Last but not least, our results show that when the crisis is in place, trend followers gradually lose their power and fundamentalists are able to drive prices to the fundamental value.

The remainder of the article is organized as follows. In Section 2, we describe the $\mathrm{BH}$ model and present the calibration technique. In Section 3 , we present numerical experiments on the three banking indices. Finally, Section 4 presents our conclusions.

\section{Model description and calibration technique}

In this section, we first briefly describe the Brock and Hommes model (BH hereinafter) and then we illustrate the technique used for the calibration ${ }^{7}$.

\subsection{The Brock and Hommes model}

The BH model, which uses the familiar demand-supply cobweb framework, considers an adaptive belief system where heterogeneous agents can choose from among different trading strategies. Two typical investors are distinguished: fundamentalists, who believe that the market price is completely determined by the fundamental value, and chartists, who think that the price can be predicted using some information about the past. The model then introduces evolutionary competition between the two strategies. At each time

\footnotetext{
${ }^{7}$ The term "calibration" used here refers to Oreskes, Shrader-Frechette and Belitz (1994, pp. 642-643).
} 
step, agents can revise their strategy according to a fitness measure based on accumulated past profits. The rewind algorithm is designed so that the strategy with the highest fitness gains a higher number of followers. Nonetheless, the algorithm introduces a certain amount of randomness, and the more successful strategy has a finite probability of not being followed. In this way, imperfect information and the bounded rationality of agents is reproduced. The randomness also helps to unlock the system from the situation where all agents follow the same strategy. The algorithm generates an endogenous switching between the two behaviors. This creates alternating periods: times when the different strategies co-exist and compete for popularity, and times when one of the two behaviors prevails and dominates the market. This alternation is the leading mechanism in generating temporary speculative bubbles.

In what follows, we describe the basic ingredients of the model. For more technical details we refer the reader to Brock and Hommes 1997 and Hommes 2001.

Agents, which are assumed to be myopic mean-variance maximizers, determine their demand for the risk asset via wealth maximization. The optimal level of risky share, $z_{h, t}=E_{h, t}\left(\bar{p}_{t+1}+y_{t+1}-R \bar{p}_{t}\right) /\left(\alpha \sigma^{2}\right)$, is a function of the expected market equilibrium price, $\bar{p}_{t+1}$, the dividend, $y_{t+1}$, the gross return of the risk free asset, $R=(1+r)>1$, the risk aversion, $\alpha$, and the conditional variance, $\sigma^{2}$. By imposing a zero supply of outside shares and different trader types, $h$, we use the optimal level of risky share to derive the market equilibrium price $\bar{p}_{t}=\frac{1}{R} \sum_{h=1}^{H} n_{h, t} E_{h, t}\left(\bar{p}_{t+1}+y_{t+1}\right)$, where $n_{h, t}$ denotes the fraction of agents $h$ at time $t$. Moreover, in the case of identical and rational agents, we obtain the fundamental price, $p_{t}^{*}=\frac{1}{R} E_{t}\left(p_{t+1}^{*}+y_{t+1}\right)$, from the market equilibrium price. In order to calculate the equilibrium and fundamental prices, agents must form their own expectations, $E_{h, t}$, on future prices and dividends. To this end, we assume that all beliefs are of the form $E_{h, t}\left(\bar{p}_{t+1}+y_{t+1}\right)=E_{t}\left(p_{t+1}^{*}+y_{t+1}\right)+f_{h}\left(\bar{x}_{t-1}, \ldots, \bar{x}_{t-L}\right)$, where $\bar{x}_{t}=\bar{p}_{t}-p_{t}^{*}$ is the deviation of the price from the fundamental price and $L$ is the number of lags. It is evident that agents believe that market and fundamental prices may not coincide due to some function $f_{h}$ that depends on the past deviation from $p_{t}^{*}$. We assume the simplest version of the model with only one lag and two simple linear trading rules. The first one describes fundamentalists, i.e., $f_{h, t}=0$, who believe that the market price will be equal to the fundamental price, or, equivalently, that the deviation, $\bar{x}_{t}$ from the fundamental price will be 0 . The second strategy describes chartists, i.e., $f_{h, t}=g \bar{x}_{t-1}$, where $g$ is the trend parameter.

For each trading day, agents update their strategy and as a consequence, the fraction, $n_{h, t}$, of investor types evolves over time. This dynamics is gov- 
erned by an endogenous fitness given by $U_{h, t}=\left(\bar{p}_{t}+y_{t}-R \bar{p}_{t-1}\right) z_{h, t}+\omega U_{h, t-1}$, where $\omega \in[0,1]$ is a memory parameter ${ }^{8}$. Each agent starts with a strategy and computes its profitability with respect to the other one. A 'Gibbs' equation, equal to $n_{h, t}=\frac{\exp \left(\beta U_{h, t}\right)}{\sum_{h=1}^{2} \exp \left(\beta U_{h, t}\right)}$, then determines the probability that the trader switches from its own strategy to the other one. This, in turn, modifies the next equilibrium market price and all the other model dynamics.

\subsection{The calibration technique}

We illustrate the calibration technique applied to validate the $\mathrm{BH}$ model. As already stressed, we choose the $\mathrm{BH}$ model because of its tractability and the immediate interpretation of the parameters in terms of behavioral attitudes. The simplicity of the model allows us to easily determine differences and similarities among the financial markets analyzed during different stages of the economic cycle.

We introduce the key ingredients of the calibration procedure:

- $p_{t}^{o}$ is the daily closing index from the real dataset. The time is $t=$ $0,1, \ldots, \tau-1$ with $\tau>1$. Specifically, $t=0$ and $t=\tau-1$ are, respectively, the first and the last observation dates used in the calibration procedure.

- $p_{h, t}=E_{h, t}\left(\bar{p}_{t+1}\right), t>0, h=1,2$, is the agent expectation of the price at time $t, \bar{p}_{t}, t>0$.

- $\bar{p}_{t}, t>0$, is the simulated equilibrium market price at time $t$.

- $p_{t}^{*}$ is the fundamental price.

- $\bar{x}_{t}=\bar{p}_{t}-p_{t}^{*}, t>0$, is the deviation from the fundamental price.

The calibration technique is composed of the following time steps:

Step $\left.i_{1}\right)$ : compute the expectation of the price for fundamentalists, $h=f$, and chartists, $h=c$ :

$$
\begin{aligned}
f_{f, t} & =0, \\
f_{c, t} & =g \bar{x}_{t-1} .
\end{aligned}
$$

\footnotetext{
${ }^{8}$ In a more complete version of the model, the cost of obtaining a "good" forecasting strategy is included in the fitness measure.
} 
Step $\left.i_{2}\right)$ : compute the agents' fitness measures:

$$
\begin{array}{r}
U_{f, t-1}=\left[\bar{x}_{t-1}-R \bar{x}_{t-2}\right] \frac{\left(-R \bar{x}_{t-2}\right)}{\alpha \sigma^{2}}+\omega U_{f, t-2}, \\
U_{c, t-1}=\left[\bar{x}_{t-1}-R \bar{x}_{t-2}\right] \frac{\left(g \bar{x}_{t-3}-R \bar{x}_{t-2}\right)}{\alpha \sigma^{2}}+\omega U_{c, t-2} .
\end{array}
$$

Step $\left.i_{3}\right)$ : compute the simulated equilibrium market price and its deviation from the fundamental price:

$$
\begin{aligned}
& \bar{x}_{t}=\left(n_{f, t-1} f_{f, t}+n_{c, t-1} f_{c, t}\right) /(1+r), \\
& \bar{p}_{t}=p_{t}^{*}+\bar{x}_{t},
\end{aligned}
$$

where $n_{f, t}, n_{c, t}$ are given by:

$$
n_{h, t-1}=\frac{\exp \left(\beta U_{h, t-1}\right)}{\sum_{h=1}^{2} \exp \left(\beta U_{h, t-1}\right)}, \quad h=f, c .
$$

Step $\left.i_{4}\right)$ if $t \leq \tau$ go to Step $i_{1}$ else stop.

We underline that in the time window of the calibration procedure, we assume the dividend process, $y_{t}$, to be constant. Constant dividends imply a constant fundamental price. This assumption makes the proposed calibration process deterministic since it does not involve any noise in the previous steps.

We now formulate the calibration problems.

Let $\mathbb{R}^{4}$ be the four-dimensional real Euclidean space and $\Phi \in \mathbb{R}^{4}$ be the vector containing the model parameters whose values have to be computed $\underline{\Phi}=\left(\alpha, p^{*}, \beta, g\right) \in \mathbb{R}^{4}$. Let $\mathcal{M} \subset \mathbb{R}^{4}$ be the set of the feasible parameter vectors defined as

$$
\mathcal{M}=\left\{\underline{\Phi}=\left(\alpha, p^{*}, \beta, g\right) \in \mathbb{R}^{4}, \alpha \geq 0, \beta \geq 0\right\} .
$$

The calibration problem considered is formulated as follows:

$$
\min _{\underline{\Phi} \in \mathcal{M}} F(\underline{\Phi})
$$

where the objective function $F(\underline{\Phi})$ is given by

$$
F(\underline{\Phi})=\sum_{t=1}^{\tau}\left(\frac{\bar{p}_{t}-p_{t}^{o}}{p_{t}^{o}}\right)^{2}, \underline{\Phi} \in \mathcal{M} .
$$


The constrained optimization problem is solved via a metric variable steepest descent method (see Recchioni and Scoccia 2000). This is an iterative procedure that, given an initial point $\Phi^{0} \in \mathcal{M}$ and making steps in the direction of minus the gradient of $F$ in a suitable metric, generates a sequence $\left\{\underline{\Phi}^{k}\right\}, k=0,1, \ldots$, of feasible vectors (i.e., $\underline{\Phi}^{k} \in \mathcal{M}, k=0,1, \ldots$ ). The gradient is computed in a suitable metric defined according to the constraints defined in $\mathcal{M}$ and rescaled in order to ensure the convergence of the iterative process. The algorithm stops when a maximum number of iterations, $M_{i t e r}$, is performed or the Euclidean distance $\left\|\underline{\Phi}^{k+1}-\underline{\Phi}^{k}\right\|$ is less than a preassigned tolerance.

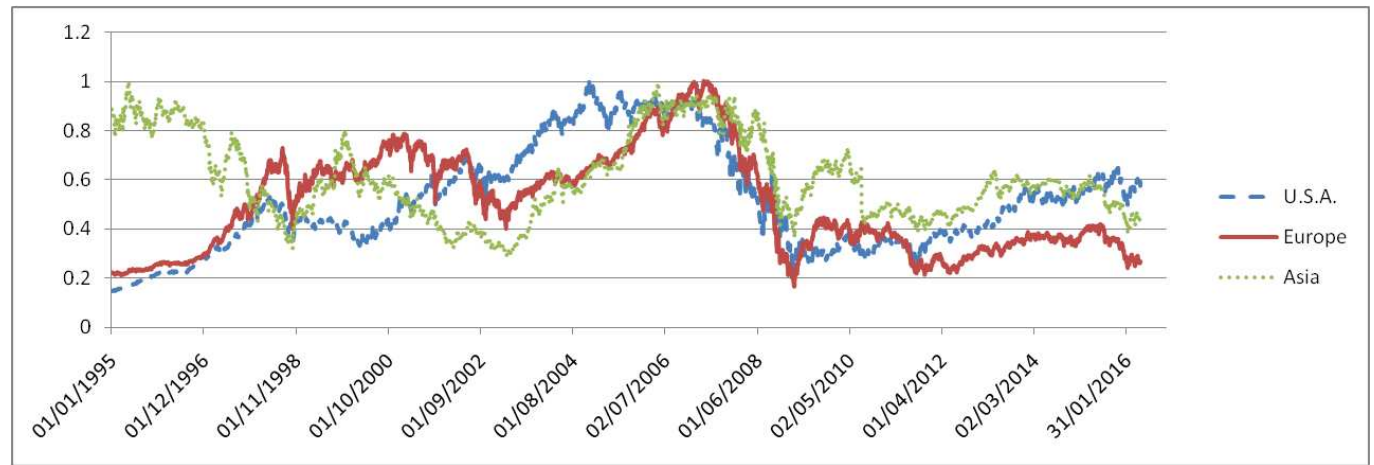

Figure 1: Re-scaled index values from December 30, $1994(t=1)$ to May 18, 2016. S\&P SmallCap 600 Financials Index (blue dashed line), STOXX Europe 600 Banks (red solid line), and STOXX Asia/Pacific 600 Banks (green dotted line).

\section{The calibration procedure at work}

\subsection{Description of the data}

In this experiment, we calibrate the parameters of the $\mathrm{BH}$ model on three banking sectoral indices representing different geographical macro areas (i.e., USA, Europe, and Asia). We use the daily closing values of the S\&P SmallCap 600 Financials Index, the STOXX Europe 600 Banks, and the STOXX Asia/Pacific 600 Banks. The data run from December 30, 1994 to May 18, 2016, corresponding to 5579 daily observations.

Figure 1 shows the re-scaled index values used in the calibration exercise. The re-scaled observed market prices are obtained simply by dividing each index value by its maximum value over the entire time period considered. 
The analyzed time series consider different phases of boom and burst that have affected financial markets in the last twenty years. Specifically, the following episodes can be mentioned: first, the mini crash on October 27 1997, caused by an economic crisis in Asia that then propagated on the US and EU markets; second, the World Trade center attack on September 11 2001, which caused a sharp drop in global stock markets; third, the internet bubble bust between July and September 2002, which resulted in a dramatic decline in stock prices across the United States, Canada, Asia, and Europe; four, the Lehman Brothers bankruptcy on September 15, 2008, resulting in an abrupt collapse of all series; and, finally, a phase beginning with the outbreak of the sovereign debt crisis on May 2010.

Figure 1 also shows a strong co-movement in the time series behavior, which confirms a strong interconnection between financial systems. This has been especially true since 2003, with a clear anticipation of the US economy on the European and Asian economies.

Before concluding the analysis of the three indices, it is worth highlighting the representativeness of this financial instrument in describing the strategies of the constituent banks. Indeed, there is empirical evidence of the co-movement of these financial aggregates with the total foreign claims of American, European, and Asian banks as published by the BIS (see Bologna and Caccavaio, 2014). This feature is highlighted by the positive and significant correlation between each index and the respective BIS data ${ }^{9}$. Specifically, we find a correlation equal to $0.678,0.575$ and 0.327 for America, Europe, and Asia, respectively.

In order to calibrate our model, the choice of the starting point, $\Phi^{0}$ must be made carefully. This problem is handled by calculating the best value of the objective function (see Eqs. 8-9) on a set of random initial points belonging to the feasible region $\mathcal{M}$.

Table 1 shows the parameter values corresponding to the smallest values of the objective functions (i.e., our starting points in the calibration exercise). By comparing the initial points for the three banking sectoral indices, it is worth noting that they are quite similar, with the only exception being for $\beta$ in the European market and $\alpha$ in the Eastern market. However, the most striking result is the absolute coincidence in the values of the parameters $g$

\footnotetext{
${ }^{9}$ In this analysis, we use the ultimate risk basis BIS consolidated banking statistics, which measure banks' exposures to different countries and sectors. They capture the worldwide consolidated claims of internationally active banks headquartered in BIS reporting countries. We consider international claims by a reporting country towards banks in counterparty countries. The available data run from 2003 to 2016.
} 
Table 1: Initial points of the BH calibration procedure.

\begin{tabular}{cccc}
\hline Parameter & US & Europe & Asia/Pacific \\
\hline$\beta$ & 0.6 & 1.5 & 0.6 \\
$\mathrm{~g}$ & 2.0 & 2.0 & 2.0 \\
$p^{*}$ & 0.45 & 0.43 & 0.47 \\
$\alpha$ & 19.2 & 19.2 & 18.2 \\
$\omega$ & 1 & 1 & 1 \\
\hline
\end{tabular}

and $\omega$.

Firstly, it is important to note that parameter $g$ describes the trendfollower behavior. A value of $g$ close to 2 has also been found in other studies involving different market indices (see Boswijk et al. 2007 and Recchioni et al. 2015). This suggests that the persistence of the trend-following strategy and its ability to deviate prices from the fundamental price is a constant feature of financial markets. It is worth noting that when $g>2(1+r)$, the simulated prices diverge from the fundamental price and move to other basins of attraction. The divergency is mathematically due to the fact that $n_{f, t} \approx$ $n_{c, t} \approx 1 / 2$ for $t>t_{0}>0$ so that from Eq. 5 we have $\bar{x}_{t}=\left(\frac{g}{2(1+r)}\right)^{t-t_{0}} \bar{x}_{t_{0}}$, $t>t_{0}$. This implies that the simulated equilibrium price does not converge to $p^{*}$ as $t \rightarrow+\infty$ when $g>2(1+r)$, while it does converge to $p^{*}$ when $g<2(1+r)$. Our estimation procedure probably forces parameter $g$ to converge to this threshold from below in order to have a longer transient period before converging to the fundamental price. During this long transient period, the trajectory is flexible and provides a good fit to the observed data.

Secondly, it is important to note that parameter $\omega$ refers to agent memory. When $\omega$ is zero, the model reproduces a situation with no memory, that is, the fitness equals the realized profit in the previous period. Otherwise, when $\omega=1$, the model generates a situation with infinite memory, that is, the fitness equals the total wealth as given by accumulated realized profits over the entire past. As clearly shown by the analysis of the starting points in Tab. 1, we detect the presence of infinite memory in all markets. Similar empirical evidence proving the presence of high memory in agent fitness is also present in the analysis of Recchioni et al. 2015. The presence of high memory also has an important theoretical consequence. As stressed by Hommes 2001, it is not clear whether the price dynamics are stable in the case of infinite memory. Specifically, it still an open question whether, in this circumstance, fundamentalists are able to stabilize the price towards its fundamental value and can mitigate the destabilizing impact of 
the trend-followers (see Brock and Hommes 1997, 1998; Hommes 2001).

\subsection{From the estimation of model parameters to the identification of banks' strategies}

In this section we investigate the ability of the calibrated model parameters to describe banks' behavior. In fact, the values of parameters resulting from calibration of the model on different markets can show differences and similarities in the behavior of agents operating in the markets considered. Two applications are considered. The first is a long-run analysis among countries (application (a)). Here the purpose is to describe the relations among the different geographical areas. In this first exercise we calibrate the parameters each year, and the final values representing the banks' strategies are obtained as an average over the whole time series.

The second application tries to identify how banks' strategies evolve over time (application (b)). The idea is to understand how banks react during different economic phases. In this second exercise, we calibrate the parameters each two months ${ }^{10}$. By generating time series of the optimal value of the calibrated parameters, this process allows us to investigate how banks dynamically change their behavior in regard to financial turmoils. The two exercises are particularly interesting because they allow us to analyze banks' behavior not only with respect to the geographic areas of interest, but also with respect to different economic phases.

Before analyzing the ability of the calibrated parameters to describe banks' strategies, we must test the ability of the calibration technique to reproduce the empirical data. To this end, we show that the model is capable of reproducing the daily price time series of the three different indices.

In this first exercise, we solve problem (8) with $\tau=200$ and $M_{\text {iter }}=1000$. In the calibration procedure, we fix parameters $\sigma=0.1$ and $r=0.01 / 250$ (daily risk free return). The initial point of the fraction $n_{h, 0}$ is 0.5 . Moreover, in the calibration procedure, we do not estimate the parameter $\omega$, which is fixed and equal to 1 (i.e., the so-called infinite memory case). This choice is supported by the analysis on the starting points shown in Tab. 1. In fact, this value corresponds to

\footnotetext{
${ }^{10}$ In the two applications (a) and (b), the length of the time window used in the calibration is constant and equal to 200. The two exercises only differ from the shifts used in the rolling-windows (i.e., 200 in (a) and 60 in (b)). Hence, we solve 26 calibration problems in (a) and 90 in (b).
} 
the smallest values of the objective function for all indices in the BH model. The initial values of the remaining parameters are fixed as in Table 1. Table 2 shows the average optimal values of the model parameters obtained from the calibration procedure. Since the calibration procedure is deterministic (i.e., it does not include any noise in the simulated equilibrium market price), the confidence interval of the estimated values of the parameters in Tables 2 are obtained by running the calibration procedure on 100 trajectories for each index. These trajectories are obtained by perturbing the logarithm of each index by adding a noise sampled from a normal distribution with zero mean and standard deviation given by $\sigma_{n}=\xi \sigma_{s}$, where $\sigma_{s}$ is the standard deviation of the observed data and $\xi$ is a constant equal to $1 \%$. The estimated values of the model parameters reported in table 2 are, therefore, obtained as average over the whole time series and trajectories. Standard deviations (St.Dev.), mean relative errors (Rel.Err.) and biases confirm that the parameters are statistically significant. Moreover, in order to assess the accuracy of our method, for each index $r$, we calculate the relative errors of the simulated equilibrium market prices. Specifically, Fig. 2 shows the quantities $e_{r, t}=\left|p_{t}^{o}-\bar{p}_{t}\right| /\left|p_{t}^{o}\right|$. We observe that, on average, the relative error is 0.00726. This indicates that the simulated market prices match the observed prices even when they are affected by abrupt changes.

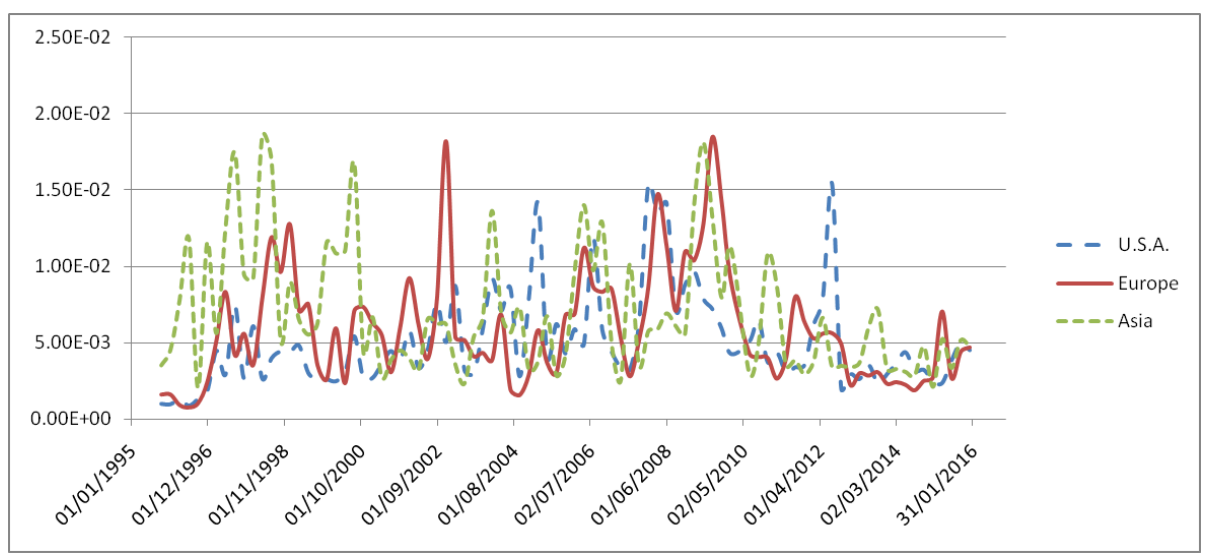

Figure 2: Relative errors, $e_{r, t}$, between the observed price and simulated equilibrium market price versus time, obtained using the $\mathrm{BH}$ model with the parameters shown in Table 2. S\&P SmallCap 600 Financials Index (blue dashed line), STOXX Europe 600 Banks (red solid line), and STOXX Asia/Pacific 600 Banks (green dotted line).

Having successfully proven our calibration for descriptive output validation, we can test its efficiency in describing banks' strategies. The results 
Table 2: Average model parameter values and average objective function values obtained with the calibration procedure. The average of each parameter is computed over the onehundred estimated values and over all the time windows.

\begin{tabular}{cccc}
\hline Parameters & S\&P Financials Index & STOXX Europe & STOXX Asia/Pacific \\
\hline$\beta$ & 1.64 & 1.75 & 1.56 \\
St. Dev & $\left(7.500 \cdot 10^{-2}\right)$ & $\left(3.682 \cdot 10^{-2}\right)$ & $\left(1.304 \cdot 10^{-2}\right)$ \\
Rel. Err. & $\left(1.457 \cdot 10^{-2}\right)$ & $\left(4.478 \cdot 10^{-3}\right)$ & $\left(9.778 \cdot 10^{-1}\right)$ \\
Bias & $\left(6.645 \cdot 10^{-3}\right)$ & $\left(2.333 \cdot 10^{-3}\right)$ & $\left(7.278 \cdot 10^{-3}\right)$ \\
\hline g & 1.95 & 1.96 & 2.00 \\
St. Dev & $\left(3.759 \cdot 10^{-2}\right)$ & $\left(8.496 \cdot 10^{-2}\right)$ & $\left(5.556 \cdot 10^{-3}\right)$ \\
Rel. Err. & $\left(3.721 \cdot 10^{-3}\right)$ & $\left(1.991 \cdot 10^{-3}\right)$ & $\left(2.147 \cdot 10^{-3}\right)$ \\
Bias & $\left(2.670 \cdot 10^{-3}\right)$ & $\left(4.483 \cdot 10^{-3}\right)$ & $\left(-4.567 \cdot 10^{-4}\right)$ \\
\hline$\alpha$ & 423.21 & 254.56 & 344.03 \\
St. Dev & $\left(1.413 \cdot 10^{+1}\right)$ & $\left(5.54 \cdot 10^{0}\right)$ & $\left(1.167 \cdot 10^{+1}\right)$ \\
Rel. Err. & $\left(1.875 \cdot 10^{-1}\right)$ & $\left(2.719 \cdot 10^{-2}\right)$ & $\left(4.986 \cdot 10^{-2}\right)$ \\
Bias & $\left(-6.178 \cdot 10^{-2}\right)$ & $\left(2.743 \cdot 10^{-3}\right)$ & $\left(-4.676 \cdot 10^{-2}\right)$ \\
\hline$p^{*}$ & $459.2403(0.29)$ & $537.725(0.28)$ & $104.024(0.29)$ \\
St. Dev & $\left(3.266 \cdot 10^{-3}\right)$ & $\left(7.913 \cdot 10^{-3}\right)$ & $\left(6.957 \cdot 10^{-3}\right)$ \\
Rel. Err. & $\left(4.970 \cdot 10^{-3}\right)$ & $\left(1.121 \cdot 10^{-2}\right)$ & $\left(1.987 \cdot 10^{-3}\right)$ \\
Bias & $\left(5.327 \cdot 10^{-3}\right)$ & $\left(7.028 \cdot 10^{-3}\right)$ & $\left(1.216 \cdot 10^{-3}\right)$ \\
\hline$F_{B H}\left(\Phi^{*}\right)$ & 0.00176 & 0.00220 & 0.00320 \\
St. Dev & $\left(6.956 \cdot 10^{-4}\right)$ & $\left(1.878 \cdot 10^{-4}\right)$ & $\left(1.492 \cdot 10^{-4}\right)$ \\
Rel. Err. & $\left(4.738 \cdot 10^{-2}\right)$ & $\left(6.435 \cdot 10^{-2}\right)$ & $\left(1.986 \cdot 10^{-2}\right)$ \\
Bias & $\left(2.432 \cdot 10^{-4}\right)$ & $\left(3.784 \cdot 10^{-4}\right)$ & $\left(1.061 \cdot 10^{-4}\right)$ \\
\hline
\end{tabular}

regarding application (a) (i.e., the intra-countries analysis) are already contained in Tab. 2. In fact, the table provides information on differences and similarities in banks' behavior operating in the different geographical areas. Specifically, Table 2 describes banks' imitative behavior $\beta$, trend follower behavior $g$, risk aversion $\alpha$, and (scaled) fundamental values $p^{*}$. It is interesting to note that all three areas are characterized by similar values of $\beta$ and $g$. This indicates the presence of collective behavior and the predominance of trend follower behavior. It is well known in agent-based literature that mechanisms of behavioral switching and collective behavior, emerging in situations with information externalities, can lead to large aggregate fluctuations (see, for instance, Lux and Marchesi 2000; Chiarella et al. 2009; Kirman and Teyssiere 2002; LeBaron and Yamamoto 2009; Tedeschi et al. 2012). This result is in line with the many bubble and crash episodes that have occurred over the last thirty years. Moreover, the high values of risk aversion char- 
acterizing all markets further support the existence of a strong instability in the investigated time series. It is worth noting that by removing the speculative bubble episodes from the investigated indices, the average risk aversion sharply decreases and reaches the values of 20.33 (st.dev $1.1413 \cdot 10^{-1}$ ), 19.35 (st.dev $5.54 \cdot 10^{-1}$ ), and 17.49 (st.dev $1.167 \cdot 10^{-1}$ ) for the US, EU, and Asian indices respectively.

We now investigate the reaction of banks when faced with financial turbulence in the last twenty years (i.e., application (b)). To this end, we solve 90 calibration problems, whose solutions generate bimonthly time series for each model parameter. All remaining parameters are those used in the previous calibration experiment.

In order to assess the robustness of the estimation procedure, we evaluate the sensitivity of the estimated parameter values with respect to the shift used in the rolling-windows. Specifically, we compare the values of application (b) with those obtained in application (a) by applying the two-sample Kolmogorov-Smirnov (KS) goodness-of-fit hypothesis test. The test confirms that the time series of model parameters, estimated using the two samples, are drawn from the same population at a significance level of $5 \%$.

Figure 3 shows the time series of the estimated parameters for the three indices ${ }^{11}$. A noteworthy feature is the strong volatility in the model parameters emerging during periods of financial instability. The episodes of financial turmoil are reflected in the dynamics of all parameters, although they are particularly evident for the Western countries (see first and second columns of Fig. 3). Specifically, we observe a sharp rise in risk aversion, $\alpha$, related to financial stress events. Parameter $\alpha$ strongly increases in all three geographical areas during the 1998 Asian financial crisis and the 2008 Lehman Brothers collapse. By analyzing the risk aversion time series of the American index (see Fig. 3, first column), we recognize other important moments of instability, such as the Twin Towers attack in 2001, the downgrading of the United States' credit rating by the credit rating agency Standard \& Poor's in 2011, and the 2013 US debt-ceiling crisis. Similar geographically localized episodes can be seen in the dynamics of the European and Asian $\alpha$ parameters. On the one hand, the European risk aversion strongly resents the sovereign debt crisis starting in 2010 (see second column of Fig. 3). On the other hand, the Asian parameter shows the 2002 internet bubble burst, the 2009 fall in GDP and exports, and the two tsunamis in 2004 and 2011 (see third column of Fig. 3).

\footnotetext{
${ }^{11}$ As in Tab. 2, we have computed the average confidence interval of the estimated values of the parameters shown in Fig. 3 over the whole time series and trajectories. Results are omitted but similar to those shown in Tab.2.
} 

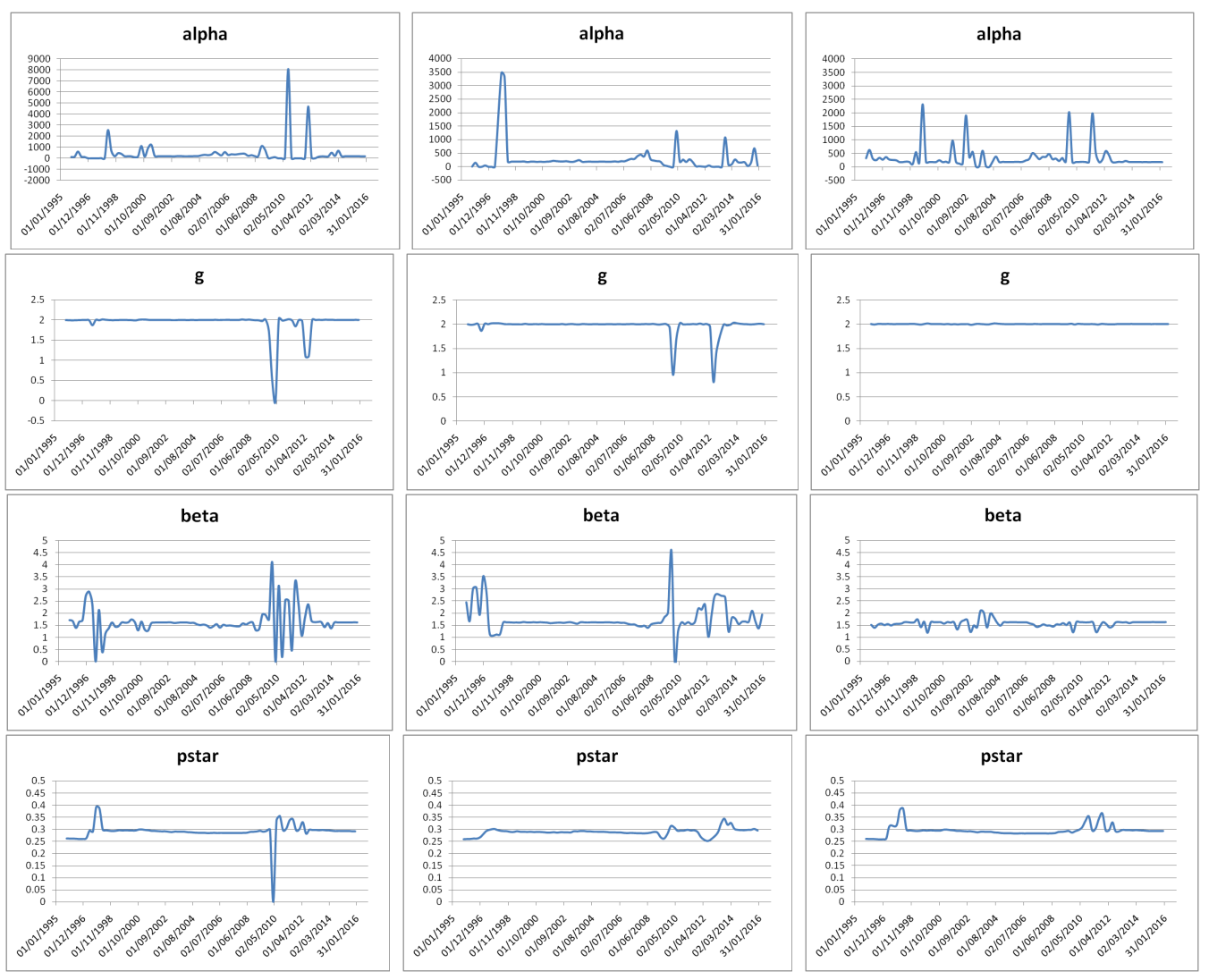

Figure 3: Risk aversion (top row), trend follower behavior (second row), imitative behavior (third row), and fundamental price (bottom row) time series for the S\&P SmallCap 600 Financials Index (first column), the STOXX Europe 600 Banks (second column), and the STOXX Asia/Pacific 600 Banks (third column).
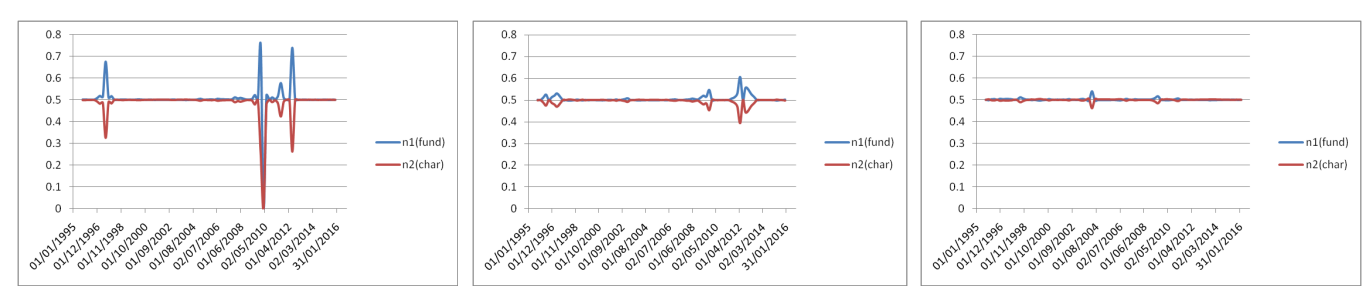

Figure 4: Time series of the fraction of fundamentalists, $n_{f}$, and trendfollowers, $n_{c}$, for the S\&P SmallCap 600 Financials Index (left panel), the STOXX Europe 600 Banks (central panel), and the STOXX Asia/Pacific 600 Banks (right panel). 
The second row of Fig. 3 displays the time evolution of trend follower behavior. As for the long-term analysis (see application (a) above), the optimum value of parameter $g$ is always around two. In accordance with other studies (see Boswijk et al 2007, Recchioni et al. 2015), this confirms the predominance of the chartist strategy and its impact in destabilizing prices. It is important to mention that chartists are investors believing that price movements can be predicted by studying past trends. Specifically, they use historical price time series to forecast future trends. In this respect, a question arises: does this strategy make sense during periods of high instability? Our empirical analysis responds negatively to this question. In fact, we detect a negative correlation between the time series of the risk aversion $\alpha$ at time $t$ and the trend follower behavior $g$ at time $t+2$. Correlation values are $-0.622,-0.253$, and -0.301 for the American, European, and Asian indices, respectively. This result indicates that after prolonged financial tensions highlighted by high riskiness, investors do not rely on information coming from historical data and, therefore, decrease $g$.

The dynamics of banks' imitative behavior, $\beta$, is shown in the third row of Fig. 3. This parameter, also known as intensity of choice, answers the question of how much agents trust information about other banks' performance. By multiplying and then amplifying the fitness measure, $U_{h}$, in the Gibbs equation (6), $\beta$ is a key parameter in determining the fraction of banks, $n_{h}$, that follow the chartist or fundamentalist strategy. A value of $\beta$ equal to zero shows complete lack of confidence in other agents' performance, while a high value of the parameter reflects a high level of trust in the success of other banks' strategies. The evolution of the parameter in the two Western markets (see first and second column) shows the presence of volatility clustering, a phenomenon reflecting the transition from quiet periods to turbulent ones. Specifically, during the 1997 Asian financial crisis and the 2008 global financial crisis, we observe erratic behavior in the parameter dynamics. This reflects a well-known phenomenon: during episodes of great uncertainty, economic agents overreact, making their choices unpredictable (see Arthur 1994 and Behrens et al. 2007). The evolution of the parameter in the Asian market instead behaves differently (see third column). Indeed, it is affected by the time series instability, but its volatility is considerably lower than in the Western markets. Specifically, in this market, the presence of volatility clustering is not observed ${ }^{12}$. It would seem that Asian

\footnotetext{
${ }^{12}$ In accordance with the empirical literature (see Cont 2001 and Tedeschi et al. 2009), we check if volatility is persistent by measuring the autocorrelation function of absolute $\beta$ for different time lags. We note that while the autocorrelation of the parameter is insignificant in the Asian market, a positive and slowly decaying autocorrelation of absolute $\beta$ is present in the two Western markets. In this case, the autocorrelation function of
} 
banks are less exposed to financial instability phenomena. This observation is confirmed by some empirical studies (see Goldstein and Xie 2009) showing that Asia is protected by its low exposure to US subprime loans and securities, ample international reserves, current account surpluses, low dependence on commodity exports, a high share of interregional trade, improved banking systems, and an ability to implement countercyclical macroeconomic policies.

Finally, the last row of Fig. 3 displays the time evolution of fundamental prices. As mentioned above, in the calibration exercise, the fundamental price is treated as a constant unknown model parameter which is estimated over the investigated time window. As the reader can see, the fundamental price is also affected by economic turbulence. However, as expected, it remains constant during quiet periods.

We now investigate the switching phenomenon in agents' strategies. The issues are why traders change behavior and the impact of switching on the price time series. Fig. 4 displays the fraction of traders, $n_{h, t}$, following the fundamentalist or chartist strategy. The figure shows time variations between the two predictors, and this is more evident in the two Western markets. This result is in line with other empirical studies (see Boswijk et al. 2007 and Recchioni et al. 2015) showing the ability of the BH model to create behavioral switching in agents' strategies.

An important assumption of the $\mathrm{BH}$ model is the mechanism of belief formation, which follows the form $E_{h, t}\left(\bar{p}_{t+1}+y_{t+1}\right)=E_{t}\left(p_{t+1}^{*}+y_{t+1}\right)+$ $f_{h}\left(\bar{x}_{t-1}, \ldots, \bar{x}_{t-L}\right)$. This assumption implies that investors are encouraged to follow the fundamentalist strategy when they observe market prices close to the fundamental price. In order to verify the reasons driving investors to choose this strategy, we analyze the correlation between the fraction of fundamentalists and the distance between the market price and the fundamental price. Specifically, is it correct to think that a price realignment toward its fundamental level induces agents to become fundamentalists? The correlations between $n_{f, t}$ and the differences between observed and fundamental price, $\left(p_{t}^{o}-p_{t}^{*}\right)$, are $-0.3343,-0.4632$, and -0.2017 for the US, EU, and Asian indices, respectively. The significant negative values of the correlations confirm the above assumption. It is important to emphasize that these values do not derive from a simple modeling assumption. In fact, they are derived using real market prices, $p_{t}^{o}$, and not the simulated market prices, $\bar{p}_{t}$. On the one hand, this result shows that the fundamentalist strategy emerges when the price is close to the fundamental price. On the other hand, the result further highlights the ability of the calibration technique to reproduce

absolute parameters is well fitted by a power law with exponent equal to 2.7 and 3.1 for the US and EU time series respectively. 
real prices.

Finally, we investigate the impact of agent beliefs on the price time series. The theoretical and empirical literature have shown the destabilizing effect of the chartist strategy on price dynamics (see, Boswijk et al. 2007; Chiarella et al. 2009; Recchioni et al. 2015 ). In line with this view, we show that price bubbles are generated by a high percentage of chartist traders. Table 3 shows the correlations between the index time series (see Fig. 1) and the lagged time series of $n_{c, t}$ (see Fig. 4). As can be seen, correlations increase at one-two

$\begin{array}{cccccc}\text { Correlation } & \text { Lag } \tau^{\prime}=0 & \text { Lag } \tau^{\prime}=1 & \text { Lag } \tau^{\prime}=2 & \text { Lag } \tau^{\prime}=3 & \text { Lag } \tau^{\prime}=4 \\ U S_{\mathbf{f}, \mathbf{t}}-n_{\mathbf{c}, \mathbf{t}-\tau^{\prime}} & 0.2148 & 0.2155 & 0.2509 & 0.2292 & 0.0028 \\ E U_{\mathbf{f}, \mathbf{t}}-n_{\mathbf{c}, \mathbf{t}-\tau^{\prime}} & 0.3683 & 0.3925 & 0.3069 & 0.1009 & 0.0498 \\ \text { Asia }_{\mathbf{f}, \mathbf{t}}-n_{\mathbf{c}, \mathbf{t}-\tau^{\prime}} & 0.2177 & 0.2769 & 0.0475 & 0.0357 & 0.0157\end{array}$

Table 3: Correlations between the index time series and the fraction of chartists, $n_{c, t-\tau^{\prime}}$, with $\tau^{\prime}=0 ; 1 ; 2 ; 3 ; 4$ at a $1 \%$ confidence level.

lags (i.e., two-four months) before the abrupt change in the indices, and they decrease at zero lag. This result confirms that large aggregate fluctuations emerge as chartists take power. Moreover, given that the time series of $n_{c, t}$ is lagged, the fraction of chartists can be considered an "indicator" capable of anticipating the financial instability.

\subsection{Robustness analysis of the piecewise constant fun- damental price}

The aim of this subsection is to empirically test the robustness of some of our modeling assumptions. Specifically, we investigate whether the assumption of a constant fundamental price over the calibration window is a robust and reliable hypothesis in that the corresponding model captures the price dynamics and the fractions of agents' strategies. To this end, we carry out two experiments. First, based on a constant fundamental price, we study the ability of our calibration technique to validate the output. Second, we compare the performance of a fundamental price given by a constant value to those given by a static Gordon model. In contrast to the analysis illustrated by Recchioni et al. 2015, where the authors evaluate the calibration performance based essentially on in-sample good fitting and out-of-sample calibration errors, here the reliability of the time series is tested in terms of the model's ability to capture some price features other than the price point-wise value. 
In fact, as stressed by a recent string of literature (see Lamperti et. al. 2018 and the reference therein), the quantitative validation of agent-based models, even using a machine learning approach, should be carried out on the model's ability to reproduce some statistical features of the price dynamics. To this end, we focus on mimicking the observed realized volatility and the observed deviations from the fundamental price, since these two quantities play a crucial role in the investor's decision-making process. In fact, on the one hand, the realized volatility of a stock/index is a nonparametric ex-post estimate of the return variation, which has been proved to be related to market sentiment (see, for example, Balcilar et al. 2018, Smale 2012). The most common realized volatility measure is the sum of the squared return realizations over a fixed time interval, typically using one to six months of daily returns (see Andersen and Benzoni 2008 for further details). This measure is also used in financial markets for hedging purposes. On the other hand, deviations from the fundamental price are often used to define sell/buy signals such as those generated by the Bank of America and Merrill Lynch Global Breath rule (BofAML Global Breath for short). This rule is based on the deviation of large- and mid-cap stocks in 47 different countries from their 50-day and 200-day moving averages, which behave like piecewise constant fundamental prices ${ }^{13}$.

Before going into the details of the analysis implemented here, it is important to highlight that all the following experiments refer to application (b). Specifically, we estimate the model parameters every 60 days by using consecutive daily data contained in a 200-day window. This window of 200 days is moved along the data time series, discarding the sixty oldest data and inserting the sixty newest data. Roughly speaking, 60 days correspond to three months since a month consists of about 21 trading days, so we are dealing with series of quarterly data.

We now start by validating the output and, in particular, studying the reliability of the agent fraction obtained with the constant fundamental value in detecting financial instability. To this end,

\footnotetext{
${ }^{13}$ Specifically, the BofAML Global Breath rule generates a buy signal when a net $88 \%$ of markets in the MSCI All Country World index are trading below their 200-day moving average and 50-day moving average. This rule is based on the fact that the MSCI ACWI captures large- and mid-cap representation across 23 developed markets and 24 emerging markets. (see https://olui2.fs.ml.com/publish/content/application/pdf/gwmol/ThemeWatch-Put-People-First.pdf for further details)
} 
following Alfarano et al. $2005^{14}$, we show that the ratio of chartist to fundamentalist is able to describe the dynamics of the realized volatility. Thus, we test for a linear relationship between the realized volatility, $R v o l_{t}$, of the index at time $t$ and the ratio $\hat{n}_{c, t} / \hat{n}_{f, t}$, where $\hat{n}_{h, t}$ is the time series of the 60-day average of agent fraction. Specifically, we investigate whether the following specific linear model is reliable:

$$
\operatorname{Rvol}_{t}=\sigma_{*} \frac{\hat{n}_{c, t}}{\hat{n}_{f, t}}+\epsilon_{t},
$$

where $R v o l_{t}$ reads as

$$
\text { Rvol }_{t}=\sqrt{\frac{252}{N} \sum_{i=t-N+1}^{t} \log \left(\frac{p_{i}^{o}}{p_{i-1}^{o}}\right)^{2}},
$$

and $\epsilon_{t}$ is the error (i.e., a Gaussian variable with zero mean and constant variance). A linear regression with zero intercept to test model (10) is carried out for each index.

Table 4 shows that model (10) captures the realized volatility dynamics for any analyzed market index, and, more interestingly, the estimated parameter $\sigma_{*}$ of Euro and U.S. indices is the same, while it differs from the parameter $\sigma_{*}$ of the Asia index. More specifically, $\sigma_{*}$ is the value of the realized volatility when the two contrasting forces in the market are equal. Thus, when the two forces are identical, we observe a larger volatility in the eastern market (annual volatility 24.44\%) than in the western markets (annual volatilities $23.02 \%$ ).

The second step of the output validation consists in proving the reliability of the estimated fundamental price, $p_{t}^{*}$. We now provide empirical evidence that the assumption of piecewise constant fundamental price is reliable. To this end, we recall that by virtue of Eqs. (1)-(5), the simulated deviation from the fundamental price (i.e., $\bar{x}_{t}=\bar{p}_{t}-p_{t}^{*}$ ) satisfies the following equation:

$$
(1+r) \bar{x}_{t}=n_{c, t} g \bar{x}_{t-1}
$$

\footnotetext{
${ }^{14}$ Alfarano et al. 2005 show that the spot volatility is proportional to the ratio of the number of chartists to the number of fundamentalists when the equilibrium price is obtained by setting the sum of the excess demands of chartists and fundamentalists equal to zero.
} 


\begin{tabular}{|cc|cc|cc|}
\hline \multicolumn{2}{|c|}{ ASIA index } & \multicolumn{2}{c|}{ EURO index } & \multicolumn{2}{c|}{ USA index } \\
\hline \multicolumn{2}{|c|}{ adj- $R^{2}$} & 0.729842 & adj- $R^{2}$ & 0.726725 & \multicolumn{2}{c|}{ adj- $R^{2}$} & 0.670481 \\
$R^{2}$ & 0.741746 & $R^{2}$ & 0.738629 & $R^{2}$ & 0.682386 \\
no. observ. & 86 & no. observ. & 86 & no. observ. & 86 \\
std err. & 0.133015 & std err. & 0.135038 & std err. & 0.153845 \\
Sign.F & $2.77 e-26$ & Sign.F & $4.58 e-26$ & Sign.F & $1.59 e-22$ \\
$\sigma_{*}$ & $0.2448(* * *)$ & $\sigma_{*}$ & $0.2301(* * *)$ & $\sigma_{*}$ & $0.2301(* * *)$ \\
conf. interval & {$[0.2135,0.2762]$} & conf. interval & {$[0.2004,0.2598]$} & conf. interval & {$[0.1961,0.2642]$} \\
\hline
\end{tabular}

Table 4: Linear model (10) with piecewise constant fundamental price: variance analysis

\begin{tabular}{|cc|cc|cc|}
\hline \multicolumn{2}{|c|}{ ASIA index } & \multicolumn{2}{c|}{ EURO index } & \multicolumn{2}{c|}{ USA index } \\
\hline adj- $R^{2}$ & 0.959724 & adj- $R^{2}$ & 0.959720 & adj- $R^{2}$ & 0.962694 \\
$R^{2}$ & 0.971489 & $R^{2}$ & 0.971485 & $R^{2}$ & 0.974458 \\
no. observ. & 86 & no. observ. & 86 & no. observ. & 86 \\
std err. & 0.119621 & std err. & 0.103866 & std err. & 0.1027436 \\
Sign.F & $7.00 e-67$ & Sign.F & $7.05 e-67$ & Sign.F & $6.88 e-69$ \\
$c$ & $1.9529(* * *)$ & $c$ & $1.9748(* * *)$ & $c$ & $1.9936(* * *)$ \\
conf. interval & {$[1.8808,2.0251]$} & conf. interval & {$[1.9019,2.0478]$} & conf. interval & {$[1.9241,2.0632]$} \\
\hline
\end{tabular}

Table 5: Linear model (14) with piecewise constant fundamental price: variance analysis

namely,

$$
\frac{\bar{x}_{t}}{n_{c, t}}=\frac{g}{(1+r)} \bar{x}_{t-1}
$$

We then test the model

$$
x_{t}^{o}=c \hat{n}_{c, t} x_{t-1}^{o}+\eta_{t},
$$

where $\eta_{t}$ is the error (Gaussian variable with zero mean and constant variance) and $x_{t}^{o}$ is the 60-day average observed deviations from the fundamental price, which reads:

$$
x_{t}^{o}=\left(\frac{1}{N} \sum_{i=t-N+1}^{t} p_{i}^{0}\right)-p_{t}^{*} .
$$

We note that the higher the reliability of the model, the smaller the difference of $c-g /(1+r)$. This is not trivial since Eq. (12) holds for the simulated deviation from the fundamental price, $\bar{x}_{t}$. This is obtained from the calibration procedure and it matches the observed deviation only via the objective function, while $x_{t}^{o}$ in Eq. (14) is an observed average deviation from the fundamental price.

Table 5 shows that the estimates of parameter $c$ are 1.9529 (Asian index), 1.9748 (Euro index), and 1.9936 (USA index). Bearing in mind that the riskfree interest rate is chosen to be $r=$ 


\begin{tabular}{|c|cc||cc|}
\hline & \multicolumn{2}{|c||}{ no-scaled indices } & \multicolumn{2}{c|}{ scaled indices } \\
\hline & ASIA index & EURO index & ASIA index & EURO index \\
\hline min & 5.34 & 28.12 & 0.21 & 0.30 \\
max & 24.79 & 92.17 & 1.00 & 1.00 \\
mean & 16.14 & 57.64 & 0.65 & 0.62 \\
median & 17.63 & 58.67 & 0.71 & 0.63 \\
St.dev & 4.49 & 13.98 & 0.18 & 0.15 \\
Skewness & -0.73 & -0.24 & -0.73 & -0.24 \\
Kurtosis & -0.64 & -0.63 & -0.64 & -0.63 \\
\hline
\end{tabular}

Table 6: Descriptive statistics of the price-to-dividend ratio.

$0.01 / 252$ and that $g=c(1+r)$, we obtain $g \approx c$. In fact, the estimated values of $c$ are consistent with the mean values of $g$ shown in Table 2 and with the median values of $g$, namely 2.0006 (ASIA index), 1.9999 (Euro index), and 1.9998 (USA index).

We conclude this subsection by comparing the performance of the $\mathrm{BH}$ model in the output validation in the case of a constant and non-constant fundamental price. Specifically, we repeat the two exercises implemented above (see models (10) and (14)) by calibrating the $\mathrm{BH}$ model using the price-to-dividend ratio. This implies that the fundamental price is given by the static Gordon model (see Boswijk et al. 2007 for further details). Thus, the deviation from the fundamental price in Eq. (5) is now equal to $\hat{x}_{t}=\delta_{t}-m$, where $\delta_{t}$ is the price-to-dividend ratio and $m$ is the fundamental price-to-dividend ratio as prescribed by the Gordon model (see Boswijk et. al. 2007 and Recchioni et al. 2015).

The empirical analysis proposed here regards the daily price-todividend ratio of Asian and European indices from March 31, 2011 to December 30, 2013 (i.e., 1502 observations for each index). Some descriptive statistics of the indices and their corresponding scaled versions are given in Table 6. The model parameters are estimated both in the case of constant and non-constant fundamental price by using a rolling window of 200 consecutive trading days with 60-day shifts. Tables 7 and 8 illustrate the results of these experiments. Specifically, Table 7 shows the results concerning the linear model (10), while Table 8 presents those concerning the model (14) with GFP and CFP, referring to the Gordon and constant fundamental prices, respectively. Moreover, the Jarque Bera p-value refers to the p-value of the Jarque Bera test for the normality of the residual while Sign.F refers to the F-test of the regression.

As the reader can see by observing the values of $a d j-R^{2}$ and 


\begin{tabular}{|cc||cc|}
\hline \multicolumn{2}{|c||}{ ASIA index (GFP) } & \multicolumn{2}{c|}{ EURO index (GFP) } \\
\hline adj- $R^{2}$ & 0.639505 & adj- $R^{2}$ & 0.879233 \\
$R^{2}$ & 0.689505 & $R^{2}$ & 0.931865 \\
no. observ. & 21 & no. observ. & 21 \\
std. err. & 0.207934 & std. err. & 0.138893 \\
Sign.F & $2.26 e-6$ & Sign.F & $2.30 e-10$ \\
Jarque Bera p-value & $1.447 \mathrm{e}-14$ & Jarque Bera p-value & 0.5185 \\
$\sigma_{*}$ & $0.3102(* * *)$ & $\sigma_{*}$ & $0.3684(* * *)$ \\
conf. interval & {$[0.2131,0.4074]$} & conf. interval & {$[0.3048,0.4320]$} \\
\hline \hline \multicolumn{2}{c||}{ ASIA index $(\mathrm{CFP})$} & EURO index $(\mathrm{CFP})$ \\
\hline adj- $R^{2}$ & 0.841565 & adj- $R^{2}$ & 0.82633 \\
$R^{2}$ & 0.891565 & $R^{2}$ & 0.87633 \\
no. observ. & 21 & no. observ. & 21 \\
std. err. & 0.061348 & std. err. & 0.094559 \\
Sign.F & $8.38 e-11$ & Sign.F & $2.96 e-10$ \\
Jarque Bera p-value & 0.2759 & Jarque Bera p-value & 0.1270 \\
$\sigma_{*}$ & $0.17(* * *)$ & $\sigma_{*}$ & $0.2478(* * *)$ \\
conf. interval & {$[0.1442,0.2003]$} & conf. interval & {$[0.2039,0.2906]$} \\
\hline \multicolumn{2}{c|}{}
\end{tabular}

Table 7: Linear model (10) with the Gordon fundamental price (GFP-upper table) and constant fundamental price (CFP-lower table): analysis of variance with Jarque Bera normality test for residuals.

$R^{2}$, the BH model with CFP always slightly outperforms the $\mathrm{BH}$ model with GCP, with the only exception being the linear model (10) in the case of the European index. However, both BH models - with CFP and GFP - provide very similar results in terms of the $\sigma_{*}$ and $c$ estimates, indicating that these constants reflect features of the price dynamics.

\subsection{How banks' size influences strategies and financial cycles}

In this section, we illustrate some preliminary results regarding the impact of banks' size on strategies and the resulting effect on financial cycles. Specifically, we show how the estimated values of the model parameters are affected by a sample made up of banks bigger in size. To this end we calibrate the BH model, as in the application b) above, to S\&P 500 Financial index. As the S\&P SmallCap 600 Financial Index, S\&P 500 Financial index is made up of U.S banks whose size is, however, significantly higher (see Tab.9 for a summary description of the two indices' components).

The left panel of Fig.5 shows the re-scaled index values used in this calibration exercise. As the reader can notice the S\&P 500 and the S\&P 600 


\begin{tabular}{|cc||cc|}
\hline \multicolumn{2}{|c||}{ ASIA index (GFP) } & \multicolumn{2}{c|}{ EURO index (GFP) } \\
\hline adj- $R^{2}$ & 0.898211 & adj- $R^{2}$ & 0.927935 \\
$R^{2}$ & 0.950843 & $R^{2}$ & 0.980566 \\
no. observ. & 20 & no. observ. & 20 \\
std err. & 0.199438 & std err. & 0.194943 \\
Sign.F & $2.00 e-13$ & Sign.F & $3.84 e-12$ \\
Jarque Bera p-value & 0.2790 & Jarque Bera p-value & 0.8382 \\
$c$ & $2.0399(* * *)$ & $c$ & $1.9667(* * *)$ \\
conf. interval & {$[1.8172,2.2627]$} & conf. interval & {$[1.7114,2.2221]$} \\
\hline \hline \multicolumn{2}{c|}{ ASIA index $(\mathrm{CFP})$} & EURO index $(\mathrm{CFP})$ \\
\hline adj- $R^{2}$ & 0.934134 & adj- $R^{2}$ & 0.93315 \\
$R^{2}$ & 0.986766 & $R^{2}$ & 0.985781 \\
no. observ. & 20 & no. observ. & 20 \\
std err. & 0.111915 & std err. & 0.12336 \\
Sign.F & $1.44 e-18$ & Sign.F & $2.47 e-18$ \\
Jarque Bera p-value & 0.6910 & Jarque Bera p-value & 0.6673 \\
$c$ & $2.012968(* * *)$ & $c$ & $1.992881(* * *)$ \\
conf. interval & {$[1.9010,2.1249]$} & conf. interval & {$[1.8779,2.1078]$} \\
\hline
\end{tabular}

Table 8: Linear model (14) with the Gordon fundamental price (GFP upper table) and constant fundamental price (CFP lower table): analysis of variance with Jarque Bera normality test for residuals.

Table 9: Summary description of the S\&P SmallCap 600 and S\&P 500 Financial indices.

S\&P $600 \quad$ S\&P 500

\begin{tabular}{ccc}
\hline Num. of Constituents & 85 & 66 \\
Max Market Cap & $3,246.48$ & $417,813.26$ \\
Min Market Cap & 346.50 & $4,744.27$ \\
Mean Market Cap & $1,479.13$ & $49,140.39$ \\
Median Market Cap & $1,291.47$ & $23,910.87$ \\
\hline
\end{tabular}

(see blue dashed line in Fig.1) strongly co-move and display similar phases of boom and burst. However, the statistical analysis shows some important differences between the two indices. Specifically, the average value of the rescaled S\&P 500 is higher than that of the S\&P 600 (i.e., 0.587 v.s 0.520 ) but with a lower variance ${ }^{15}$ (i.e., 0.18 v.s 0.22 ). As the empirical literature well documents, price volatility is a good proxy of financial and macroeconomic uncertainty (see Baum et al. 2008; Ghosal and Loungani, 2000; Berardi and Tedeschi 2017). The fact that big financial institutions are more trustable

\footnotetext{
${ }^{15}$ Other important summary statistics for the S\&P 500 Financial index (S\&P SmallCap 600 Financial Index) are: minimum 0.23 (0.19), maximum 0.97 (0.93), skewness 0.03 (0.55) and ex. kurtosis $-0.76(-0.76)$.
} 

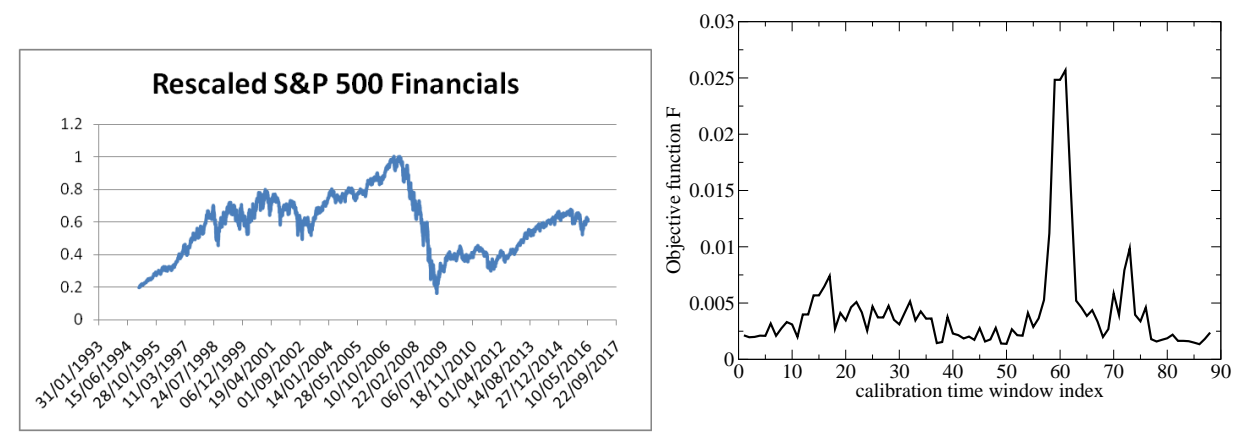

Figure 5: Re-scaled S\&P 500 Financial index from December 30, $1994(t=1)$ to May 18, 2016 (left side). Objective function values obtained with the calibration procedure (right side).

in the eyes of investors and, consequently, their price less volatile, is a welldocumented fact. On the one hand, indeed, the number of large banks failing is quite small, as evidenced by the fact that over 465 U.S banks failed from 2008 to 2012 , only 60 were big, that is with assets higher than $\$ 1.0$ billion (see Federal Deposit Insurance Corporation 2013). On the other hand, the belief that the biggest financial institutions are so vital to the economy that it would be disastrous if they went bankrupt makes stockholders less uncertain in investing in this type of institutions. This second point is closely related to the idea of "bailout", and the several studies on "too big, too complex, too interconnected, or too many to fail" (see Brown \& Dinc 2011; Cheng \&Van Cayseele 2010; Dam \& Koetter 2012; Duchin \& Sosyura 2014; Farhi \& Tirole 2012; Marinc \& Rant 2014). It is worth noting that the lower index volatility associated to big financial institutions must not be confused with their lower systemic risk. The systemic impact of the large financial institutions is undoubtedly much higher but their probability of bankruptcy is certainly much lower (see Caccioli et al. 2012; Iori et al., 2006; Lenzu and Tedeschi, 2012; Tedeschi et al., 2012a). The analysis of the systemic risk, seen as the direct and indirect spillover effects arising from the bankruptcy, or the financial distress of a shocked organism, is outside the scope of our study and incompatible with the $\mathrm{BH}$ framework.

Before analyzing the effect that banks' size has on strategies, the right panel of fig. 5 shows the accuracy of our calibration technique in reproducing the index dynamics. Specifically, the low average value of the objective function, equal to 0.0042 (st.dev $2.252 \cdot 10^{-4}$ ), indicates the ability of the estimation 
procedure to accurately interpret the dataset ${ }^{16}$.

We are now ready to assess the repercussions that banks bigger in size have on the estimated model parameters. To this end, we just focus on the estimated parameters reproducing different dynamics than those of the S\&P 600 index ${ }^{17}$. Top panel of Fig. 6 reproduces the estimated values of the two
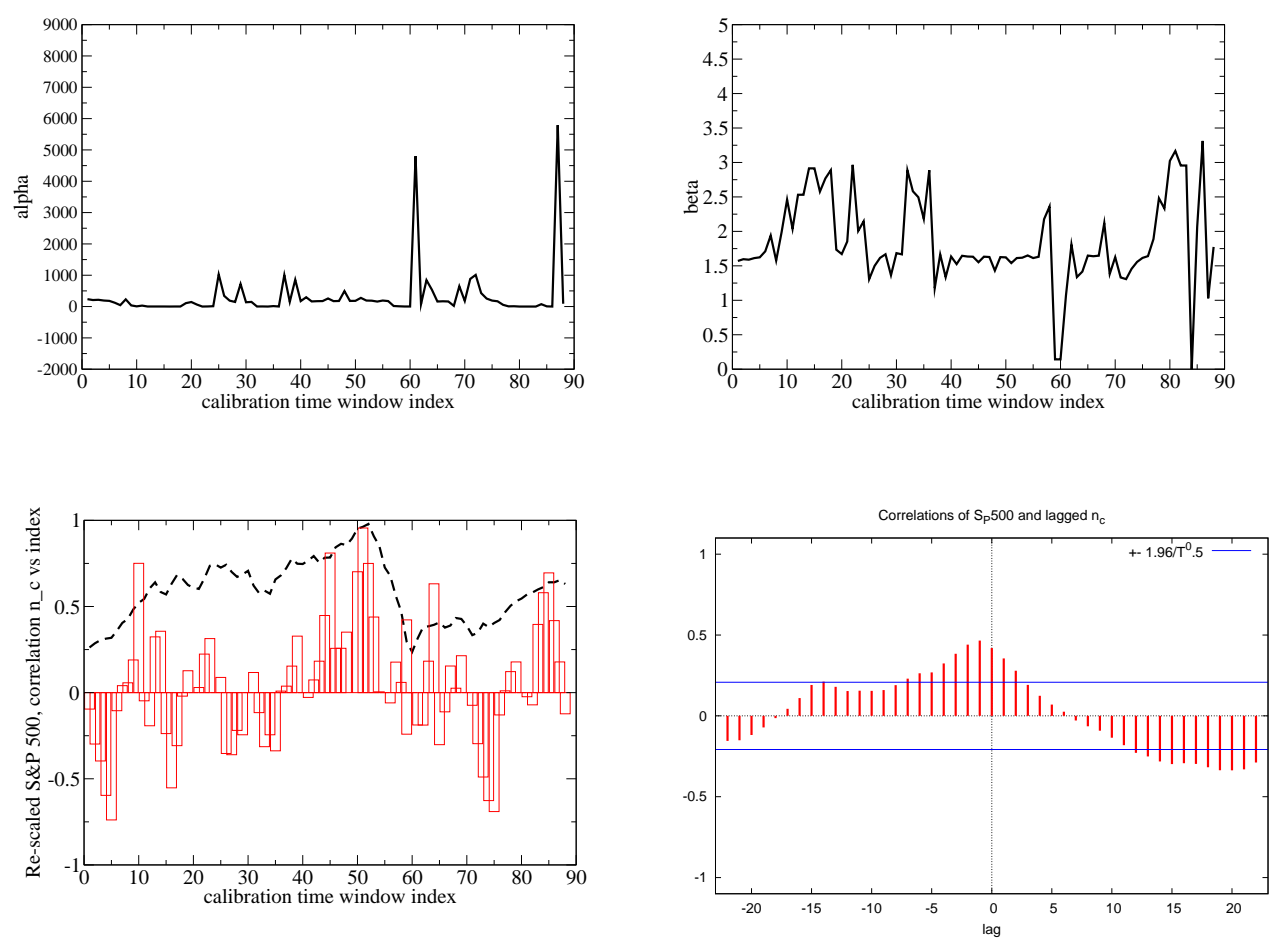

Figure 6: Risk aversion (top left), imitative behavior (top right), correlation between the index time series and the lagged time series of $n_{c, t}$ over the time (bottom left) and its average value over the time and simulation (bottom right). Results refer to the S\&P 500 Financial index.

model parameters that statistically deviate from those of the S\&P 600 index: namely the risk aversion, $\alpha$ (left side), and the intensity of choice, $\beta$ (right side). With regard to the risk aversion, it is worthy of note that the average value of $\alpha$ is lower for the the S\&P 500 than for the S\&P 600 (i.e. 302.4 with st.dev $1.112 \cdot 10^{+1}$ vs 423.2 with st.dev $\left.1.413 \cdot 10^{+1}\right)$. Moreover, by comparing the

\footnotetext{
${ }^{16}$ In order to assess the robustness of the estimation procedure on the S\&P 500 index, also in this analysis, we have computed the average confidence interval of the estimated values of all parameters over the whole time series and 100 trajectories

${ }^{17}$ Results of the other estimated parameters' time series are omitted because similar to those shown in the left column of Fig.3.
} 
time series of the estimated risk aversion parameter for the S\&P 500 and the S\&P 600 (see Fig.3, top row on the left), we can notice that the time series of the first index is less sensitive to the crises affecting the economy. Specifically, big banks seem to be less affected by the several financial turmoils perturbing the investigated series. An important exception is at the Lehman Brothers collapse. This episode has a much stronger adverse impact on the risk aversion of big financial institutions than of small ones. This is demonstrated by the higher value that the $\alpha$ parameter assumes for the S\&P 500 than for the S\&P 600 (i.e. 4800 v.s 1100). Curiously, this event affects big banks with a noticeable time lag. In fact, we notice that the parameter rises to $\tau=60$ (i.e, April 30, 2009) for the S\&P 500 index while to $\tau=58$ (i.e., November 13, 2008) for the S\&P 600. A possible insight into this time lag is attributable to the reliability of large banks. To undermine their credibility, it has been necessary no just the single episode "Lehman Brother", but the systemic amplification generated by the episode itself, and of course, this amplification has taken time.

With regard to the intensity of choice, the top right panel of Fig. 6 shows the dynamics of this parameter. Specifically, big banks during crisis periods show the tendency to strengthen their intensity of choice. While small banks, during financial shocks, show strong uncertainties in choosing their strategy, as shown by strong oscillations in $\beta$, big banks show a more coherent and stable behavior, as highlighted by the clear ascending or descending trend of $\beta$ which gradually strengthens over time. This means that big financial institutions are more confident in choosing and maintaining their strategies. This is also confirmed by the lower switching affecting big banks compared to small ones. Specifically, the average switching between fundamentalists and chartists takes the values of 0.19 (st.dev. 0.02) and 0.36 (st.dev. 0.05), for the S\&P 500 and 600, respectively ${ }^{18}$.

Last but not least the bottom panel of Fig. 6 shows the lagged correlation between the S\&P 500 index in $t$ and the fraction of chartists in $t-1$ over the time (left side) and its average value over time and trajectories (right side). As the figure shows strong periods of instability are anticipated by a significant rise in the fraction of chartists. Once again, trend-followers destabilize the system by creating considerable bubbles. However, before the bubble achieves its maximum, chartists lose their power, as confirmed by the sharp decline in the correlation value, and fundamentalists take the lead by exploding the bubble and re-lowering the index value. The trend followers'

\footnotetext{
${ }^{18}$ The average switching between fundamentalists and chartists is defined as the average number of times, over calibration time-windows and simulations, the fraction of fundamentalists is less of 0.5 .
} 
anticipatory effect in destabilizing prices is clearly shown in the bottom right panel of Fig. 6, where the correlation wave between the chartists' fraction and the index first increases from $t-4$ up to $t-1$, and then decreases from $t$.

\section{Conclusions}

In this work, we have analyzed the ability of a well calibrated agent-based model to describe agents' strategic behavior through the value of the estimated parameters. By calibrating the BH model on daily data of three bank indices (i.e., US, EU, and Asian indices - S\&P 500 SmallCap 600, STOXX Europe 600 Banks and STOXX Asia/Pacic 600 Banks) running from 1994 to 2016, we have answered some questions regarding both similarities and differences in the behavior of banks operating in different geographical areas and the evolution of banks' strategies during several economic phases.

We have detected many similarities among the investigated areas. Specifically, all three markets are characterized by the presence of collective behavior and the predominance of trend follower behavior. Moreover, high values of risk aversion characterizing all markets further support the existence of a strong instability in the time series investigated. Additionally, our analysis, has also highlighted an important difference among markets. In fact, Western countries have appeared strongly perturbed by the financial instability affecting the periods considered. The parameters of these countries have shown volatility clustering indicating long transition periods between frenzied and calm times. Specifically, the erratic behavior of the intensity of choice parameter has supported this phenomenon and highlighted the incapacity of traders to cope with uncertainty.

With regard to the evolutionary analysis, our technique has shown some important features in banks' behavior. First, we have observed a decline in the power of the chartist strategy during crises. This indicates that prolonged financial tensions induce banks not to rely on information on past prices. Moreover, our results have shown the emergence of switching behaviors during pre/post periods of financial instability. On the one hand, we have noted that fundamentalists work as a thermostat of the society by realigning prices to the fundamental price. On the other hand, our analysis has clearly revealed the destabilizing power of chartists. These traders, in fact, not only generate asset bubbles, but also herald their arrival. In this respect, our study has shown that large aggregate fluctuations in the indices' time series are preceded by an increase in the number of trend-followers. 


\section{References}

[1] Agliari, A., Hommes, CH., Pecora, N. 2016. Path dependent coordination of expectations in asset pricing experiments: A behavioral explanation. Journal of Economic Behavior and Organization,121(C),15-28.

[2] Alfarano, S., Lux, T., Wagner, F., 2005. Estimation of Agent-Based Models: The Case of an Asymmetric Herding Model. Computational Economics, 26 (1), 19-49.

[3] Andersen, T. G., Benzoni, L. 2008. Stochastic Volatility. Federal Reserve Bank of Chicaago WP 2009-04. Available at SSRN: http://dx.doi.org/10.2139/ssrn.1076672

[4] Arthur, W. B. (1994). Inductive reasoning and bounded rationality. The American economic review, 84(2), 406-411.

[5] Balcilar, M., Gupta, R., Kyei C. (2018). Predicting stock returns and volatility with investor sentiment indices: A reconsideration using a nonparametric causality-in-quantiles test. Bulletin of Economic Research 70(1), 0307-3378.

[6] Bank for International Settlements (2018), http://www.bis.org/statistics/consstats.htm.

[7] Bao, T., Duffy, J., Hommes, C. 2013. Learning, forecasting and optimizing: An experimental study. European Economic Review, Elsevier, 61(C),186-204.

[8] Bargigli, L., Gallegati, M., Riccetti, L., Russo, A., 2014. Network analysis and calibration of the leveraged network-based financial accelerator. Journal of Economic Behavior \& Organization, 99109-125.

[9] Bargigli, L., 2017. Chapter 8 - Econometric Methods for Agent-Based Models. Editor(s): Mauro Gallegati, Antonio Palestrini, Alberto Russo, Introduction to Agent-Based Economics. Academic Press, Pages 163189, ISBN 9780128038345.

[10] Bargigli, L., Riccetti, L., Russo, A, Gallegati, M., 2018. Network calibration and metamodeling of a financial accelerator agent based model. J Econ Interact Coord 1-28. https://doi.org/10.1007/s11403-018-0217-8

[11] Baum, C. F., Caglayan, M., Stephan, A., \& Talavera, O. (2008). Uncertainty determinants of corporate liquidity. Economic Modelling, 25(5), 833-849. 
[12] Behrens, T. E., Woolrich, M. W., Walton, M. E., and Rushworth, M. F. (2007). Learning the value of information in an uncertain world. Nature neuroscience, 10(9), 1214-1221.

[13] Berardi, S., and Tedeschi, G. (2017). From banks' strategies to financial (in) stability. International Review of Economics \& Finance, 47, 255-272.

[14] Bernanke B., Gertler M., 1990. Financial fragility and economic performance. Q J Econ 105(1):87-114

[15] Bernanke B., Gertler, M. 1995. Inside the black box: the credit channel of monetary policy transmission. J Econ Perspect 9(4):27-48.

[16] Blaug, M. 1992. The Methodology of Economics: Or, How Economists Explain. Ed. Cambridge University Press.

[17] Bologna, P., \& Caccavaio, M. (2014). Euro Area (cross-border?) banking. Questioni di Economia e Finanza (Occasional Papers) 228, Bank of Italy, Economic Research and International Relations Area.

[18] Boswijk, H.P., Hommes, C., Manzan, S., 2007. Behavioral heterogeneity in stock prices. Journal of Economic Dynamics and Control, 31(6), 19381970 .

[19] Brown, C. O., and I. S. Dinc (2011), Too Many to Fail? Evidence of Regulatory Forbearance When the Banking Sector Is Weak. Review of Financial Studies 24(4), 1378-1405.

[20] Brock, W., \& Hommes, C. 1997. A Rational Route to Randomness. Econometrica, 65(5), 1059-1095. doi:10.2307/2171879.

[21] Brock, W.A., Hommes, C.H. 1998. Heterogeneous beliefs and routes to chaos in a simple asset pricing model. Journal of Economic Dynamics and Control, 22, 1235-1274.

[22] Caccioli, F., Catanach, T. A., \& Farmer, J. D. (2012). Heterogeneity, correlations and financial contagion. Advances in Complex Systems, 15(Supp02), 1250058.

[23] Chen, S.H., Chang, C.L, Du, Y.R., 2012. Agent-based economic models and econometrics. The Knowledge Engineering Review 27, 187-219.

[24] Chen, PC. 2015. Banks' Acquisition of Private Information About Financial Misreporting. Accounting Review, Forthcoming. Available at SSRN: http://ssrn.com/abstract $=2636066$. 
[25] Chen, Z. Lux, T., 2015. Estimation of sentiment effects in financial markets: A simulated method of moments approach. FinMaP-Working Paper 37, University of Kiel, Department of Economics, Kiel.

[26] Cheng, X., and P. Van Cayseele (2010). State Aid and Competition in Banking: The Case of China in the Late Nineties. Review of Business and Economics 56(1), 10-29.

[27] Chiarella, C., Iori, G., Perello, J., 2009. The impact of heterogeneous trading rules on the limit order book and order flows. Journal of Economic Dynamics and Control 33 (3), 525-553.

[28] Clark, A. 1997. Economic Reason: The Interplay of Individual Learning and External Structure. in The Frontiers of the New Institutional Economics, Academic Press, Chapter XII (pp. 269-290).

[29] Cont, R. 2001. Empirical properties of asset returns: stylized facts and statistical issues. Quantitative Finance, Vol 1.

[30] Dam, L., and Koetter, M. (2012). Bank bailouts and moral hazard: Evidence from Germany. The Review of Financial Studies, 25(8), 23432380 .

[31] Delli Gatti D, Guilmi C, Gaffeo E, Giulioni G, Gallegati M, 2005. A new approach to business fluctuations: heterogeneous interacting agents, scaling laws and financial fragility. Journal of Economic Behavior and Organization 56: 489-512.

[32] De Long, J.B., Shleifer, A., Summers, L., Waldmann, R., 1990. Positive feedback investment strategies and destabilizing rational speculation. Journal of Finance 45 (2).

[33] de Jong, E., Verschoor, W. F. C., Zwinkels, R. C. J., 2009. behavioral heterogeneity and shift contagion: Evidence from the asian crisis. Journal of Economic Dynamics and Control 33, 1929-1944.

[34] de Jong, E., Verschoor, W. F. C., Zwinkels, R. C. J., 2010. Heterogeneity of agents and exchange rate dynamics: Evidence from the EMS. Journal of International Money and Finance 29, 1652-1669.

[35] Duchin, R., and Sosyura, D. (2014). Safer ratios, riskier portfolios: Banks' response to government aid.Journal of Financial Economics, 113(1), 1-28. 
[36] Farhi, E., and J. Tirole (2012), Collective Moral Hazard, Maturity Mismatch and Systemic Bailouts, American Economic Review 102, 60-93.

[37] Fasika, H., and Pozo, S. 2008. Currency crisis contagion and the identification of trasmition channels. International Review of Economics \& Finance 17 (4), 572-588.

[38] Federal Deposit Insurance Corporation, 2013. Failed Bank List. Website: https://www.fdic.gov/bank/individual/failed/banklist.html.

[39] Ghonghadze, J., Lux, T., 2015. Bringing an elementary agent-based model to the data: Estimation via GMM and an application to forecasting of asset price volatility. FinMaP-Working Paper 38, University of Kiel, Department of Economics, Kiel.

[40] Ghosal, V., and Loungani, P. (2000). The differential impact of uncertainty on investment in small and large businesses. Review of Economics and Statistics, 82(2),338-343.

[41] Gilli, M., Winker, P., 2003. A global optimization heuristic for estimating agent based models. Computational Statistics and Data Analysis 42, 299-312.

[42] Gori M., Ricchiuti G., 2018. A Dynamic Exchange Rate Model with Heterogenous Agents. Journal of Evolutionary Economics, 28(2), 399415 .

[43] Grilli, R., Tedeschi, G. and Gallegati, M. 2015. Markets connectivity and financial contagion. J Econ Interact Coord 10: 287. doi:10.1007/s11403014-0129-1.

[44] Grilli, R., Tedeschi, G. and Gallegati, M. 2015b. Bank interlinkages and macroeconomic stability. International Review of Economics \& Finance $34,72-88$.

[45] Gropp, R., H. Hakenes, and I. Schnabel (2010), Competition, Riskshifting, and Public Bail-out Policies. Review of Financial Studies 24(6), 2084-2120.

[46] Goldstein, M., Xie, D. (2009). The impact of the financial crisis on emerging Asia. Peterson Institute for International Economics Working Paper, (09-11). Heemeijer, P., Hommes, C., Sonnemans, J., Tuinstra, J., 2009. Price stability and volatility in markets with positive and negative expectations feedback: an experimental investigation. Journal of Economic Dynamics and Control 33, 1052-1072. 
[47] Hommes, C., 2001. Financial markets as nonlinear adaptive evolutionary systems. Quantitative Finance, 1(1), 149-167.

[48] Hommes, C., Sonnemans, J., Tuinstra, J., van de Velden, H. 2005. Coordination of Expectations in Asset Pricing Experiments. Review of Financial Studies, 18(3), 955-980.

[49] Husler, A., Sornette, D., Hommes, C.H. 2013. Super-exponential bubbles in lab experiments: Evidence for anchoring over-optimistic expectations on price. Journal of Economic Behavior and Organization, 92(C), 304316.

[50] Iori, G., Jafarey, S., \& Padilla, F. G. (2006). Systemic risk on the interbank market. Journal of Economic Behavior \&Organization, 61(4), 525-542.

[51] Kalemli-Ozcan, S., Papaioannou, E., and Perri, F. 2013. Global banks and crisis transmission. Journal of international Economics, 89(2), 495510.

[52] Kirman, A.P. 1992. Whom or What Does the Representative Individual Represent? Journal of Economic Perspectives, 6 (2): 117-136., doi:10.1257/jep.6.2.117.

[53] Kirman, A., Teyssiere, G., 2002. Microeconomic models for long-memory in the volatility of financial time series. Studies in Nonlinear Dynamics and Econometrics 5, 281.

[54] Kirman, A. 2010. Complex economics: individual and collective rationality. Ed. Routledge.

[55] Kukacka, J., Barunik, J., 2017. Estimation of Financial Agent-Based Models with Simulated Maximum Likelihood. Journal of Economic Dynamics and Control 85, 21-45.

[56] Lamperti, F., Roventini, A., Sani, A. (2018). Journal of Economic Dynamics \& Control, 90, 366-389.

[57] LeBaron, B., Yamamoto, R., 2009. The impact of imitation on long memory in an order-driven market. Eastern Economic Journal 34 (4), 504-517.

[58] Lengnick, M., Wohltmann, H.W., 2013. Agent-Based Financial Markets and New Keynesian Macroeconomics - A Synthesis. Journal of Economic 
Interaction and Coordination, 8, 1-32. Agent-based model calibration using machine learning surrogates.

[59] Lenzu, S., \& Tedeschi, G. (2012). Systemic risk on different interbank network topologies. Physica A: Statistical Mechanics and its Applications, 391(18), 4331-4341.

[60] Lux, T., Marchesi, M., 2000. Volatility clustering in financial markets: a micro simulation of interacting agents. International Journal of Theoretical and Applied Finance 3.

[61] Marin, JM., Akin, O., Peydro, JL. 2016. Anticipating the Financial Crisis: Evidence from Insider Trading in Banks. CEPR Discussion Paper No. DP11302. Available at SSRN: http://ssrn.com/abstract $=2786904$.

[62] Manzan, S., Westerhoff, F. H., 2007. Heterogeneous expectations, exchange rate dynamics and predictability. Journal of Economic Behavior and Organization 64, 111-128.

[63] Marinc, M., and Rant, V. (2014). A cross-country analysis of bank bankruptcy regimes. Journal of financial stability, 13, 134-150.

[64] Naimzada, A.K., Pireddu, M., 2014. Dynamic Behavior of Product and Stock Markets with a Varying Degree of Interaction. Economic Modelling, 41, 191-197.

[65] Oreskes, N., Shrader-Frechette, K., Belitz, K., 1994. Verification, validation, and confirmation of numerical models in the earth sciences. Science, 263 (5147), 641-646.

[66] Orhangazi, O., 2008. Financialization and capital accumulation in the non-financial corporate sector. Camb. J. Econ. 32(6), 863-886.

[67] Proaño, C.R., 2011. Exchange Rate Determination, Macroeconomic Dynamics and Stability under Heterogenous behavioral FX expectations. Journal of Economic Behavior and Organization, 77, 177-188. xxxxc

[68] Recchioni, M.C., Scoccia, A. 2000. A stochastic algorithm for constrained global optimization. Journal of Global Optimization, 16, 257270 .

[69] Recchioni, M.C., Tedeschi, G., Gallegati, M. 2015. A calibration procedure for analyzing stock price dynamics in an agent-based framework. Journal of Economic Dynamics and Control, 60, 1-25. 
[70] Reitz, S., Slopek, U., 2009. Non-linear oil price dynamics: A tale of heterogeneous speculators? German Economic Review 10 (3), 270-283.

[71] Rochon LP, Rossi S 2010. Has It happened again? Int J Polit Econ 28(4):832-862.

[72] Smale, L.A. (2016). Time-varying relationship of news sentiment, implied volatility and stock returns. Applied Economics, 48, 4942-4960.

[73] Shoham, Y., Powers, R., Grenager, T. 2007. If Multi-Agent Learning is the Answer, What is the Question? Artificial Intelligence 171, 365-377.

[74] Stigler, G., Becker, G. 1977. De gustibus non est disputandum. American Economic Review. 67 (2): 76 .

[75] Tedeschi, G., Iori, G., Gallegati, M. 2009. The role of communication and imitation in limit order markets. European Physical Journal B, 1, 489-497.

[76] Tedeschi, G., Iori, G., Gallegati, M. 2012. Herding Effects in Order Driven Markets: The Rise and Fall of Gurus. J. Econ.Behav.Organisazion, 81, 82-96.

[77] Tedeschi G., Mazloumian, A., Gallegati, M., Helbing, D. 2012a. Bankruptcy Cascades in Interbank Markets. PLoS ONE 7(12): e52749. doi:10.1371/journal.pone.0052749.

[78] Tedeschi G., Gallegati, M., Mignot, S., Vignes, A. 2012b. Lost in transactions: The case of the Boulogne s/mer fish market. Physica A: Statistical Mechanics and its Applications, 391 (4), Issue 4, 1400-1407.

[79] Tesfatsion, L., Judd, K. L. (Eds.). 2006. Handbook of computational economics: agent-based computational economics (Vol. 2). Elsevier.

[80] Tesfatsion, L., 2013. Website on Validation of ACE: http://www.econ.iastate.edu/tesfatsi/empvalid.htm.

[81] Westerhoff, F., 2012. Interactions between the real economy and the stock market: A simple agent-based approach. Discrete Dynamics in Nature and Society. 